\title{
An Integrated Assessment of Eco-hydrological Processes of A Mountainous Catchment using Geospatial Modelling and Remote Sensing
}

Cenk Donmez, Suha Berberoglu, Ahmet Cilek

Landscape Architecture Department-Remote Sensing and GIS Lab, Cukurova University, TURKEY, Adana, 01330, cdonmez@cu.edu.tr

Abstract-The aim of this study was to carry out a comparative analysis of catchment runoff generation and forest Net Primary Production (NPP) in a semi-arid Mediterranean environment. The methodology hydrological and NPP modelling to assess their ecohydrological interactions. Model simulations showed that temperature highly contributed to NPP variations of needle-leaf forests and grasslands.

Keywords - Hydrological modelling, NPP, Mediteranean, Remote Sensing, Turkey.

\section{Introduction}

Vegetation is also known as one of the major deriver of watershed hydrology components such as evapotranspiration, runoff and soil-water interaction. The interaction between these cycles needs to be understood. This is a critical issue in the Eastern Mediterranean region, where the water resources are limited and will be affected severely by climate change and anthropogenic impacts [1;2]. Addressing to this argument, the prediction of runoff components (surface, sub-surface and interflow baseflow) and NPP are important issues for the coming decades to define eco-hydrological interactions for the decision-makers at watershed scale [3; 4].

The study comprises an innovative and operational application by utilizing various techniques, including remote sensing, geographical information systems (GIS), in situ measurements, biogeochemical and hydrological modelling. The ultimate objective was to evaluate how the water and productivity linked during a hydrological year.

\section{Study Area}

Karahacili subcatchment located in Goksu Watershed selected for this study has a very high local environmental quality and sensitivity in respect to water resources (Fig. 1).

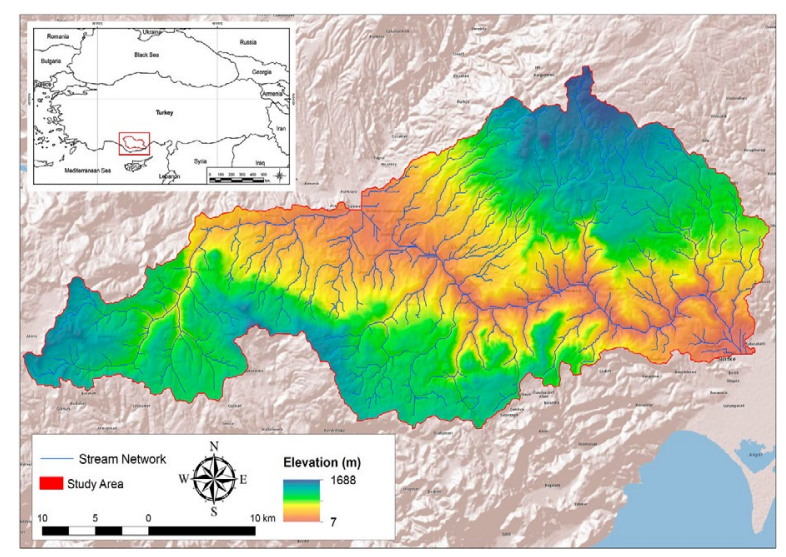

Fig. 1. Location of the Karahacili subcatchment, Turkey.

The subcatchment given as study area covers $1157 \mathrm{~km}^{2}$. It comprises pure and mixed conifer forests. These forests are classified as a Mediterranean evergreen cover type. 


\section{Methods}

The study consisted three steps: (i) estimating runoff generation using J2000 model, (ii) modelling NPP using CASA model and (iii) implementing multiple regression algorithms to derive temporal and comparative analysis of runoff and NPP.

\section{Hydrological modelling}

The J2000 hydrological model was used in our study is a modular process-oriented hydrological system, which implements encapsulated process modules for simulating hydrologic processes such as evapotranspiration, interception, snow, soil water and lateral water movement, groundwater recharge and recession and lateral flow processes in the river network. The model J2000 requires spatially distributed information related to topography, land use, soil type and hydrogeology to estimate specific attribute values for each modelling unit. The model was run for nine-year data record. The Nash-Sutcliffe efficiency (NSE) [5], between observed and simulated values was used to evaluate model performance.

\section{NPP modelling}

Land and ocean models, calculates NPP as a function of the driving energy for photosynthesis, the absorbed photosyntheticallyact ive (400 to $700 \mathrm{~nm}$ ) solar radiation (APAR), and an average light utilization efficiency $(\boldsymbol{\varepsilon})$.

$$
\mathrm{NPP}=\mathrm{APAR} \times \boldsymbol{\varepsilon}
$$

The monthly NPP flux, defined as net fixation of $\mathrm{CO} 2$ by vegetation, is computed in CASA on the basis of light-use efficiency [6]. The fundamental relation in the CASA model is

$$
\mathrm{NPP}=f(\mathrm{NDVI}) \times \mathrm{PAR} \times \boldsymbol{\varepsilon} \times g(T) \times h(W)
$$

where APAR (in megajoules per square meter per month) is a function of NDVI and downwelling photosynthetically active solar radiation (PAR) and $\boldsymbol{\varepsilon}$ (in grams of $\mathrm{C}$ per megajoule) is a function of the maximum achievable light utilization efficiency $\boldsymbol{\varepsilon}$ adjusted by functions that account for effects of temperature $g(T)$ and water $h(W)$ stress. Whereas previous versions of the CASA model [7;8] used a normalized difference vegetation index (NDVI) to estimate FPAR, the current model version instead relies upon canopy radiative transfer algorithms which are designed to generate improved FPAR products as inputs to carbon flux calculations. The model was utilized to predict annual regional fluxes in terrestrial net primary production at variable degrees of $\mathrm{C}$, depending on the yearly conditions, with terrestrial net production. Several diverse datasets were used in this research. Calculation of annual terrestrial NPP is based on the concept of light-use efficiency, modified by temperature, rainfall values and solar radiation scalars. In addition, percentage of tree cover, land cover map of the region, soil texture and NDVI (normalized difference vegetation index) were used to constitude this model.

\section{Temporal assessment of runoff and NPP}

Temporal assessment of runoff and NPP amounts were carried out by a multiple regression algorithm. This assessment was based on the modelling outputs. Multiple regression algorithm was applied to each model output and a comparative analysis of those variables was done on monthly and annual basis. The relationship was evaluated with the determination coefficient $\left(r^{2}\right)$ that was ranged between 0 and 1 .

\section{Results}


Hydrological modelling was carried out in Karahacili subcatchment from 1 January 2003 to 31 December 2012. The model period was split into calibration (1 January 2003-31 December 2006) (Fig. 2) and validation periods (1 January 2007-31 December 2012). Observed runoff in the study area was used to compare the model outputs.

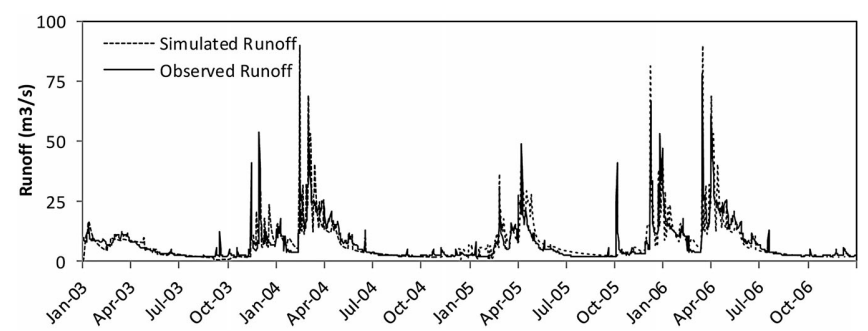

Fig. 2. Observed and simulated runoff in calibration period (2003-2006).

In the calibration period, the NSE was estimated 0.74, which shows that the hydrological quantities were simulated with reasonable accuracy. The application of the parameter set for the subcatchment showed that the hydrological model produced reliable results for a complex Mediterranean watershed. Validation period is shown in Fig. 3 (2007-2012).

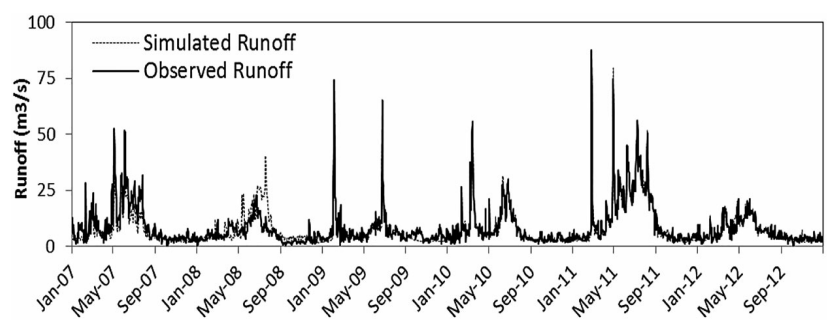

Fig. 3. Observed and simulated runoff in validation period (2007-2012).

The simulation results of total runoff generation were compared to observed runoff records obtained from DSI (State Hydraulic Works of Turkey) from 2003 to 2012. Larger increases were estimated in runoff from March to April, due to a typical of higher rainfalls in the Mediterranean during spring. Moreover, runoff occurred in January and February in response to the rainfall in winter. For summer season, a decrease in runoff was simulated due to dry season in the region. Therefore, the model results showed that the J2000 was simulating the runoff as it was expected in a hydrological year. Runoff generation map of the Karahacili subcatchment is given in Fig. 4.

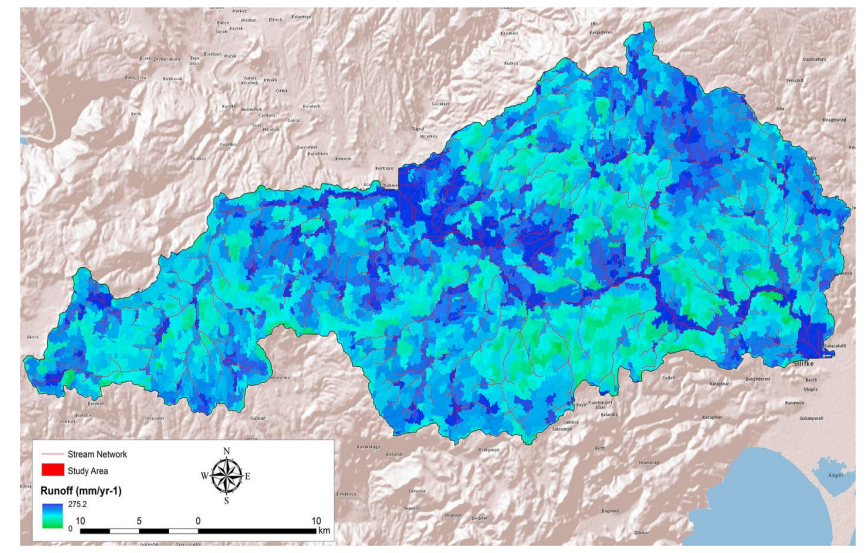

Fig. 4. Runoff generation map of the Karahacili subcatchment. 
The model output map clearly shows that the runoff is subsequently routed through the subcatchment along flow paths determined by the topography depending upon slope, flow velocity and soil characteristics along the flow lines.

Daily fluxes and states of carbon for defined forest stands to the entire subcatchment were simulated using CASA model. According to the CASA model results, the mean annual NPP differed significantly among all months ranged from 6.84 to $212.03 \mathrm{gC} \mathrm{m}-2$ year-1. Annual NPP represents the total amount of NPP of in the study area in a year. Monthly distributions of NPP reflect the interaction between physical (e.g. photosynthetic active radiation and precipitation) and biological processes (e.g. species composition, microbial activity and interactions among organism and land cover).

The CASA model was applied for each land cover type. Then, the results for the each land cover type were aggregated and the total annual NPP of the subcatchment were derived. NPP amounts for different land cover/use types was shown in Fig. 5.

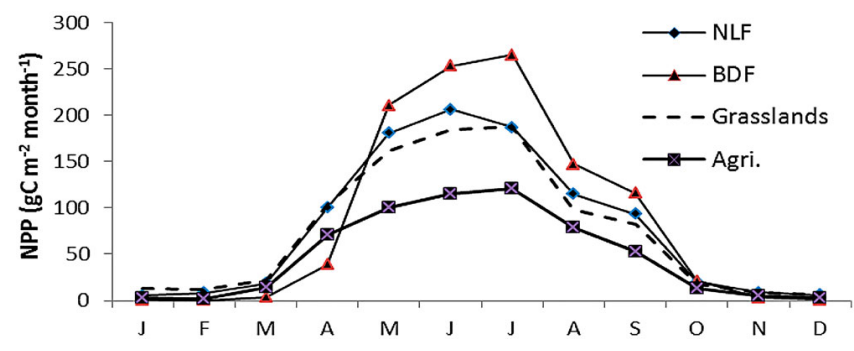

Fig. 5. NPP amounts for different land cover/use types.

Spatial distribution of NPP was also produced by incooperating the model results in GIS environment. Total annual NPP map of Karahacili subcatchment is shown in Fig.6.

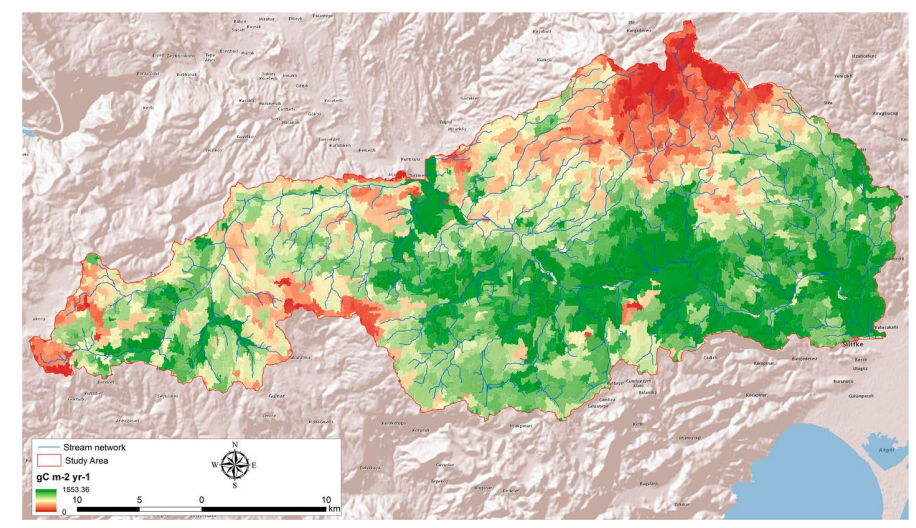

Fig. 6. Annual total NPP map of Karahacili subcatchment.

Temporal changes between temperature, precipitation, runoff and NPP were compared to determine the effect of the hydrological and climatic factors on NPP. The distribution between monthly NPP and temperature, total runoff, evapotranspiration and runoff components are shown in Fig. 7. 


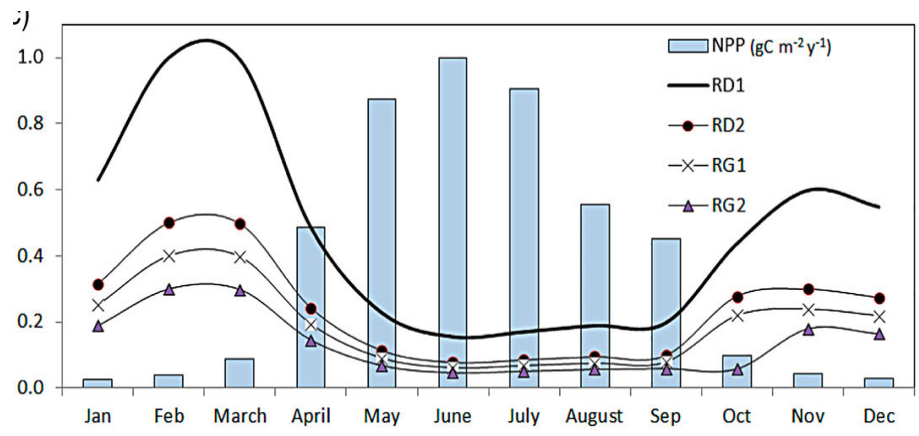

Fig.7. The distribution between monthly NPP and temperature, total runoff, evapotranspiration and runoff components.

The scattering plots showed that precipitation changes affected NPP variations marginally. Annual NPP over two different vegetation types would not respond well to precipitation changes. The relationship showed that the inter-annual variability in NPP is unable to explain the variations in precipitation across the study area. The coefficient of determination between runoff and NPP was 0.37 for NLF and 0.41 for shrublands. This correlation between runoff and NPP showed that the runoff relationship with NPP was moderate in the study area.

\section{Conclusions}

This study has importance to determine interactions of different ecosystem functions such as water and carbon in the form of NPP. Data on streamflow, land cover, soils, geology and climate allowed the study to perform a comprehensive evaluation of a Mediterranean system by comparing different components of the water and carbon cycles. The evaluation of the hydrology and forest relationships was based on the NPP and runoff components. The results of the study for a Mediterranean ecosystem showed that methods combining remote sensing, hydrological and biogeochemical modelling have strong potential for monitoring carbon balances, hydrological variables and their interactions. Coupling of these model approaches should be considered for future studies.

The outputs of the modelling applications of our study also comprised the NPP and runoff maps for the study area. Maps are powerful ways of visualizing the properties of ecosystem such as NPP and water. Displaying the maps of those important ecosystem variables could allow researchers and decision-makers to monitor short- and long-term environmental changes. This mechanism will bring an opportunity for decision-making by providing geospatial information driven by sophisticated modelling approaches. It should be noted that it is a challenging issue to represent complex relationships between ecosystem functions using different model approaches. The model simulations contain a large amount of uncertainty. This mainly occurs due to different functions and number of parameter values to relate the rate variables of carbon and water fluxes to $\mathrm{CO}^{2}$ concentration, temperature and precipitation.

\section{References}

[1] Meric, B. T: 2004. "Water Resources Management And Turkey". Journal Of Geology Engineering 1: 27-38.

[2] Donmez, C., Krause, P. Berberoglu S., Helmschrot J., And Thomas E: 2009. Earth Observation And Water Cycle Science Towards A Water Cycle Multi-Mission. Observation Strategy Symposium, Organized By European Space Agency (Esa), Frascati, Italy, On Cd. 
[3] Jackson, R. B., S. R. Carpenter, C. N. Dahm, D. M. Mcknight, R. J. Naiman, S. L. Postel, And S. W. Running: 2001. "Water İn A Changing World. Ecological Applications" 11 (4): $1027-1045$.

[4] Tague, C. L., And Band E.: 2004. "Rhessys: Regional Hydro-Ecologic Simulation System An Object - Oriented Approach To Spatially Distributed Modeling Of Carbon, Water, And Nutrient Cycling”. Earth Interactions 8 (19): 1-42.

[5] Duan, Q., J. Schaake, V. Andréassian, S. Franks, G. Gotet1, H. V. Gupta, Y. M. Gusev, F. Et Al.: 2006. "Model Parameter Estimation Experiment (Mopex): An Overview Of Science Strategy And Major Results From the Second and Third Workshops". Journal of Hydrology 320: $3-17$.

[6] Monteith, J.L (1972). "Solar radiation and productivity in tropical ecosystems". Journal of Applied Ecology 9: 747- 766.

[7] Potter C.S., A. Davidson, S. Klooster, D. Nepstad, H. Gustavo, H. Denegreiros, V. Brooks (1998). "Regional Application of an Ecosystem Production Model for Studies of Biogeochemistry in Brazilian Amazonia”, Global Change Biology pp. 315-333.

[8] Potter, C.S., J.T. Randerson., C.B Field, P.A. Matson, P.M. Vitousek, H.A. Mooney, S.A. Klooser (1993). "Terrestrial ecosystem production: A process model based on global satellite and surface data. Global Biogeochemical Cycles", 7: 811-841. 